\title{
Review
}

\section{The Maintenance of Genome Integrity is Tissue-Specific}

\author{
Tetsuya Ono ${ }^{1}$, Hironobu Ikehata, Yoshihiko Uehara and Jun-ichiro Komura \\ Department of Cell Biology, Graduate School of Medicine, Tohoku University, Sendai, Japan
}

(Received January 4, 2006; Accepted January 18, 2006)

\begin{abstract}
In order to understand how mutagens behave and act in vivo, it is important to understand how the integrity of the genome is maintained and protected in each specific tissue. Although several lines of evidence suggest that the systems used to protect and maintain the genome can change or are modified during cellular differentiation processes, and when cells alter their status from a proliferating to a non-proliferating state, data on individual tissues is very limited. Recent studies on the age-dependent accumulation of spontaneous mutations in transgenic mice clearly indicate that there is tissue-specificity when examining genome maintenance and protection. The genome is most unstable in epithelial tissues of the small and large intestine when compared to 13 other organs and tissues. The genome is highly protected in brain, skin and testis. Studies of the molecular nature of specific mutations suggest the presence of unique tissue-specific mechanisms leading to the formation of mutations in specific tissues. Studies of mutations in DNA repair gene deficient mice have shown that some of the genes involved in mismatch repair are indispensable in many tissues for the maintenance of the genome. The Xpa and $X p c$ genes involved in nucleotide excision repair have also been shown to be important in some tissues. However, the studies reported to date are only a beginning, and a complete comprehensive picture of the maintenance and repair of the genomic integrity in individual tissues remains to be developed.
\end{abstract}

Key words: DNA Damage, DNA Repair, DNA Protection, Mutation, Tissue-Specificity, Genome Integrity

\section{Introduction}

In living cells, the genome is now known to be in a dynamic rather than in a static state (1). The genome suffers from chemical alterations induced by exogenous factors such as background radiation, ultraviolet light and mutagenic chemicals, and suffers as well from endogenous factors such as reactive oxygen species (ROS). Damage can appear on one strand of the DNA double helix, or on both strands when inter-strand cross-links and double strand breaks are formed. To prevent the loss of genetic information which can result from such DNA damage, cells can reduce possible damage by two ways; through the quenching of ROS molecules with superoxide dismutase, catalase, glutathione etc., and the other through the repair of DNA damage. The DNA repair system is complex and the number of genes involved in this activity is currently estimated to be about 130 (2). If the damaged DNA is replicated before it is repaired, the loss of genetic information can be fixed and then become a mutation. Some repair processes are also known to be error-prone and can result in the formation of a mutation during attempted repair efforts $(3,4)$. These processes are illustrated schematically in Fig. 1.

One important question of current interest is whether or not the DNA damage and repair scheme described in Fig. 1 is operating in a similar manner in all of the various tissues and organs in an organism. Several lines of evidence currently suggest that DNA damage and repair mechanisms do not function in the same manner in all locations. For example, the expression levels of many different DNA repair genes are reported to change during embryonic and developmental processes (5). In addition, in several cultured cell lines, DNA repair profiles have been shown to change during cellular differentiation processes $(6,7)$. Hashimoto et al. reported that human lymphocytes can repair radiationinduced single-strand breaks in DNA almost 10-fold more efficiently when they were shifted from a nonproliferating $\mathrm{G}_{0}$ stage to a proliferating stage by the presence of phytohemagglutinin (8). Recently, Bielas and Heddle found that ethylnitrosourea (ENU)-induced DNA damage is neither repaired nor mutagenic if the cells are kept in a non-dividing quiescent state, but repair and mutagenicity are both observed if the cells enter into a proliferative phase (9). This suggests that a mutation can be induced by an error in the repair process and/or during the replication of damaged DNA. Another elegant study was reported by Arai et al. using regenerating mouse liver (10). They examined the levels of 8 -hydroxyguanine $(8 \mathrm{OHG})$ and mutations in mice treated with the oxidizing agent potassium bromate $\left(\mathrm{KBrO}_{3}\right)$. They used repair gene (Oggl)

${ }^{1}$ Correspondence to: Tetsuya Ono, Department of Cell Biology, Graduate School of Medicine, Tohoku University, 2-1 Seiryo-Machi, Aoba-Ku, Sendai 980-8575, Japan. Tel: +81-22-717-8131, Fax: +81-22-717-8136, E-mail: tono@mail.tains.tohoku.ac.jp 


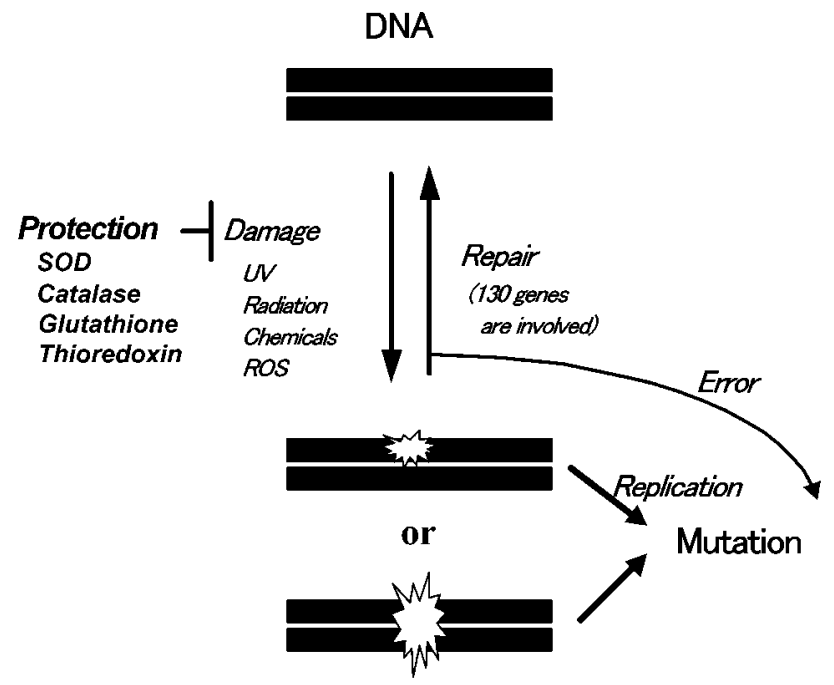

Fig. 1. Schematic illustration of DNA damage, protection and repair processes.

DNA is damaged routinely by reactive oxygen species (ROS), chemical mutagens, background radiation, and ultraviolet light (UV). The damage can be manifested on one strand of DNA (e.g. as base damage), or on both DNA strands (e.g. as a double strand break). Cells have the ability to minimize the damage in two ways; one is protection by reducing the levels of damaging agents (primarily ROS), and the other is by repair of damaged DNA. Mutations are induced if DNA is replicated before the damage is repaired. Some repair processes are also associated with a high incidence of mutation formation, and these processes are called error-prone repair.

deficient mice which allow the efficient induction of $8 \mathrm{OHG}$ in liver DNA. Although the administration of $\mathrm{KBrO}_{3}$ raised the $8 \mathrm{OHG}$ level 37-fold above controls, mutations were not induced. After regeneration of the liver induced by partial hepatectomy, the mutation level increased 3.5-fold. During the regeneration process, the $8 \mathrm{OHG}$ sites were not repaired. The predominant type of mutation induced was G:C to T:A base substitution, which is the type of mutation expected to be induced by $8 \mathrm{OHG}$ (11). Thus it is likely that the mutations were induced by the incorporation of an A into a newly synthesized DNA strand in a position opposite from the $8 \mathrm{OHG}$ site by DNA polymerase rather than by the misrepair of the 8OHG site. If these last two observations are applicable to non-proliferating tissues such as the brain and heart, many DNA damaging agents, if not all, could conceivably be non-mutagenic in these tissues.

In other recent work, a tissue-specificity for the maintenance of genome integrity was explicitly shown in aging studies. The presence of mutations in DNA is one of the final indicators of genomic stability, and the development of transgenic mice suitable for mutation assays has provided a powerful tool to study mutations in all kinds of tissues (12). The use of these mice to observe an age-dependent accumulation of spontaneous mutations has provided evidence for the existence of tissue-specific maintenance of genome integrity. The aim of this review is to provide a summary of the work and current findings concerning tissue-specificity and the maintenance of genomic integrity.

\section{Spontaneous mutations in newborn and young mice show little tissue-specificity}

Mutations in different tissues of newborn and young mice were examined in different strains of transgenic mice (12-14). Different strains of mice show different levels of mutation, and this probably reflects the size of the genes examined (e.g. about $2 \times 10^{-5}$ for $1.1 \mathrm{kbp}$ long lacI in Big-Blue ${ }^{\mathrm{TM}} v s$ about $5 \times 10^{-5}$ for $3.1 \mathrm{~kb}$ long lac $Z$ in Muta ${ }^{\mathrm{TM}}$ and Line 60 (14)), the type of mutation to be detected (e.g. a very low level of mutation such as $2 \times$ $10^{-6}$ is observed in deletion mutation assay system on the $\mathrm{red} / \mathrm{gam}$ gene in gpt-delta mouse (12)), and/or the location of the genes in the mouse genome (more than 10 -fold of differences are observed in the spontaneous mutation levels when the same gene was integrated in different chromosomes $(15,16))$. However, in terms of mutation frequencies and the molecular nature of the mutations observed, the variation among the different tissues within each strain was very small. Other recent studies on 6 different parts of the digestive tract of the Muta $^{\mathrm{TM}}$ mouse also support this conclusion (17, see also Fig. 2,3). This suggests that genomes in different tissues are all maintained or repaired in a similar manner during the embryonic and post-natal early stages.

\section{Mutation levels reveal tissue-specificity in mid- dle age and old age mice}

Age-dependent changes in mutant frequencies in the epithelial tissues of the stomach and distal small intestine in Muta $^{\mathrm{TM}}$ mice are shown in Fig. 2. An almost linear age-dependent increase is observed in these two tissues. The rate of increase, however, differs between the two tissues. Similar studies have been done with 10 other tissues and they are summarized in Fig. $3(17,18)$. Mutants accumulate most rapidly in the epithelial tissues of the small and large intestine resulting in a 5- to 6-fold increase in mutant frequencies during 2 to 23 months of age. The three parts of the small intestine, the proximal-, medial- and distal-parts showed similar rates of increase. Intermediate rates of increase in mutant frequencies were observed in the esophagus, stomach epithelium, spleen, liver and heart. The stomach included both fore- and glandular portions. The increases in mutant frequencies in skin, brain and testis were very slight. Similar studies were also performed with Line 60 and Big-Blue ${ }^{\mathrm{TM}}$ mice (14). The transgenes used for mutation assay in these mice are lac $Z$ in plasmid pUR288 (Line 60) and lacI in lambda (Big-Blue ${ }^{\mathrm{TM}}$ ), whereas it is lacZ in lambda in Muta ${ }^{\mathrm{TM}}$ mouse. The data, except for the digestive tract of the Muta ${ }^{\mathrm{TM}}$ 

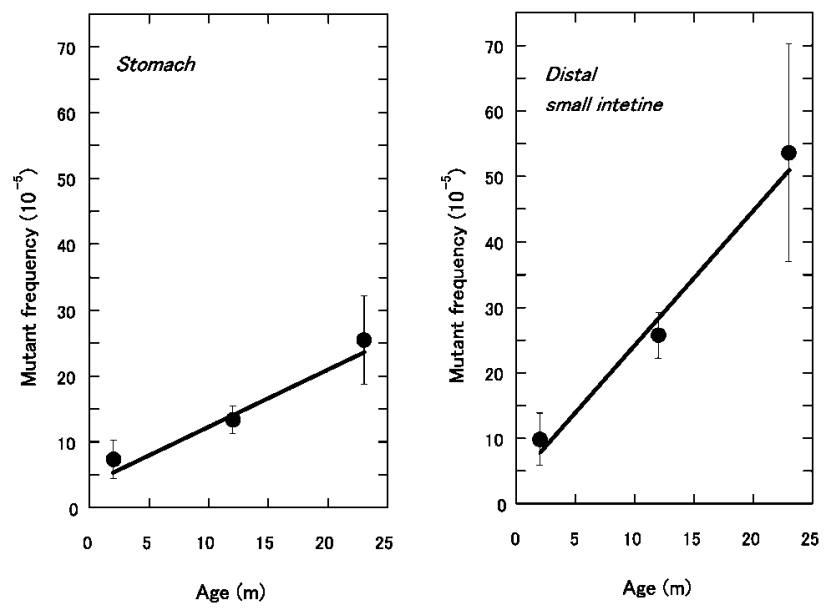

Fig. 2. Age-associated increase of mutant frequency in the epithelial tissues of the stomach and the distal small intestine in Muta ${ }^{\mathrm{TM}}$ mice.

An almost linear increase is observed in both tissues. The rate of increase shows differences between the two tissues. The data for young and old mice were taken from reference 17.

mouse, have been summarized extensively by Hill et al. $(14,19)$. Table 1 shows a simplified summary of all the data currently available. The pattern of increasing mutant frequency rates in the spleen, liver, heart, brain, small intestine and testis are similar in the two or three different strains of mice. One puzzling result is observed in sperm. A very slight or no age-dependent increase in mutant frequency was observed in cells derived from testicular seminiferous tubules in the three strains, while a large increase was detected in the sperm of Big-Blue ${ }^{\mathrm{TM}}$ mice. Since the cells in the seminiferous tubules contain many post-meiotic cells as well as pre-meiotic cells, this difference might indicate that mutations can be formed during the maturation process of sperm in old mice. Further studies are needed to clarify this point.

These data clearly indicate that genome maintenance is different in different tissues. It is likely that levels of DNA damage, genome protection and/or repair capability become tissue-specific as mice mature, thus this specificity is not easily observable as spontaneous mutations at young ages. However, as the animals age, and as a sufficient number of mutations accumulate, the tissue-specificity becomes explicit during middle and old ages in mice.

\section{What is the cause of tissue-specificity?}

Investigation of the molecular nature of the observed mutations may provide clues to the origin of tissue specific mutation formation, because some types of mutation can be attributable to specific causes. For example, $\mathrm{G}: \mathrm{C}$ to $\mathrm{A}: \mathrm{T}$ base substitutions at $\mathrm{CpG}$ sites are induced by the deamination of methylated cytosine at these sites (20); G:C to A:T base substitutions at CC, $\mathrm{TC}$ and $\mathrm{CT}$ dipyrimidine sites are induced by ultraviolet

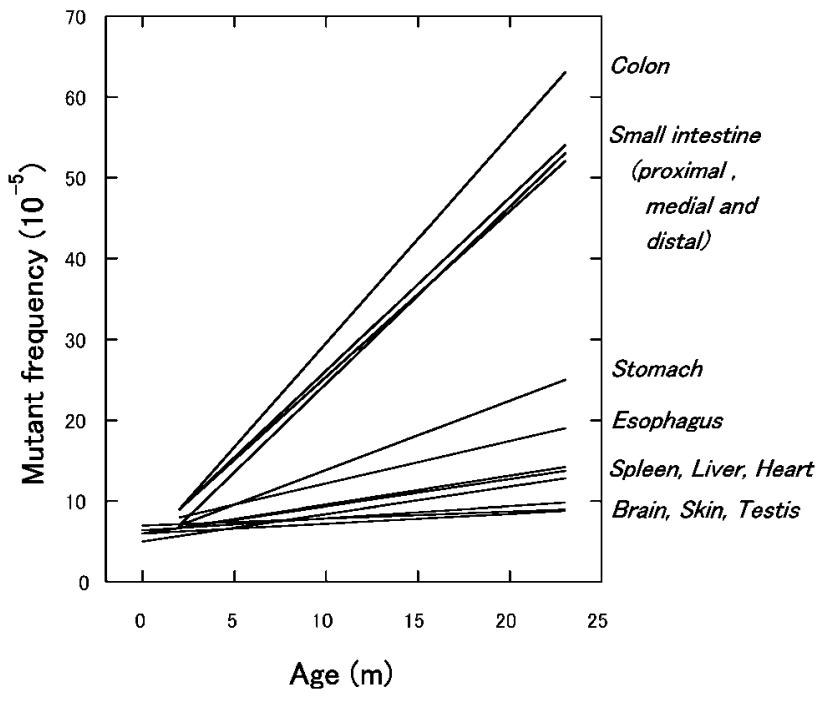

Fig. 3. Age-dependent increases of mutant frequencies in 12 different tissues in Muta ${ }^{\mathrm{TM}}$ mice.

In newborn or 2 month old mice, the levels of mutations were similar in all of the tissues examined. The mutant frequencies show a wide range in middle age and old age mice. $(17,18)$ This suggests that genome maintenance and repair systems vary among the different tissues. The genomes in epithelial tissues in the small and large intestine were the least protected among the tissues examined, while the genomes in brain, skin and testis were highly protected.

Table 1. Changes in the rate of mutation accumulation during the aging process

\begin{tabular}{lccc}
\hline \hline \multicolumn{1}{c}{ Tissue } & Muta $^{\mathrm{TM}}$ & Line60 & Big-Blue $^{\mathrm{TM}}$ \\
\hline Spleen & ++ & & ++ \\
Liver & ++ & + & ++ \\
Kidney & & & ++ \\
Heart & ++ & ++ & \\
Skin & + & & \\
Urinary bladder & & & $++{ }^{*}$ \\
Adipose tissue & & & + \\
Brain & + & - & - \\
Forebrain & & & - \\
Cerebellum & & & - \\
Esophagus & ++ & & \\
Stomach, epithelium & ++ & & \\
Small intestine & & +++ & \\
$\begin{array}{l}\text { Proximal small intestine, epithelium } \\
\text { Medial small intestine, epithelium }\end{array}$ & +++ & & \\
$\begin{array}{l}\text { Distal small intestine, epithelium } \\
\text { Colon, epithelium }\end{array}$ & +++ & & \\
Testis & +++ & & \\
Sperm & +++ & & \\
\hline
\end{tabular}

The data in this table are summarized from three references: 14,17 and 19 . Symbols used:

- ; no increase

$+;$ an increase of less than 2 -fold in about 2 years of life.

++ ; an increase of 2 - to 3 -fold in about 2 years of life.

+++ ; an increase of more than 3 -fold in about 2 years of life.

*Approximately a 3-fold increase was observed during 1.5 to 12 months of age. 
light $(21,22) ; \mathrm{G}: \mathrm{C}$ to $\mathrm{T}: \mathrm{A}$ base substitutions are induced by oxidized guanine $(8 \mathrm{OHG})(11)$; deletion mutations are induced by ionizing radiation $(23,24)$; deletions in repeat sequences are caused by the slippage of DNA polymerase (25), etc. Comparisons of the molecular nature of mutations in young and old mice have been examined in many tissues $(14,18,19)$. In most tissues, no significant differences between young and old mice were observed in the mutation spectrum. This suggests that

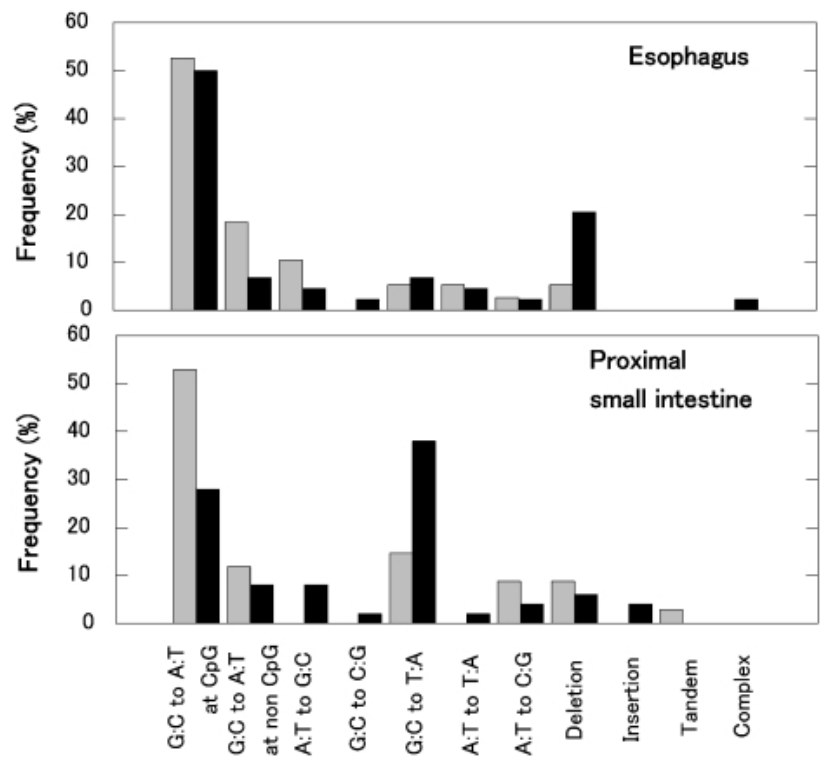

Fig. 4. Mutation spectra for spontaneous mutations in the esophagus and proximal small intestine in young and old Muta ${ }^{\mathrm{TM}}$ mice.

Grey columns indicate 2 month old mice and black columns indicate 23 month old mice. The molecular nature of the mutations can be judged by the frequency of the different types of mutations observed which is called the mutation spectrum. Comparison of mutation spectra of the esophagus between young and old animals reveals an elevation of deletion type mutations in old mice. Since most of the deletion mutations are single base deletions in repeated sequences (17), it is likely that the mismatch repair system which is responsible for repairing this type of damage could be insufficient in the esophagus. A comparison of the mutation spectra in the proximal small intestine shows a specific increase of $\mathrm{G}: \mathrm{C}$ to $\mathrm{T}: \mathrm{A}$ mutations. Since this is a typical mutation induced by oxidized guanine ( $8 \mathrm{OHG})$, this tissue might be subject to high levels of ROS-induced damage, or contains an insufficient level of the repair enzyme (Ogg1) responsible for removal of such damage. The graphs are plotted from raw data in the original paper (17). similar mechanisms are involved in the formation of mutations throughout life in these tissues. In some tissues, however, specific types of mutation were present at elevated levels in old age. Typical examples of this are shown in Fig. 4 (17). In the esophagus of old Muta ${ }^{\mathrm{TM}}$ mice there is an elevated level of deletion mutations. Since most of the deletions were single base deletions at single base repeats, it is likely that mismatch repair activity is inadequate in the adult esophagus. Epithelial tissue in the proximal small intestine in old mice revealed a rise of $\mathrm{G}: \mathrm{C}$ to $\mathrm{T}$ :A events. A similar tendency was also observed in the medial part of the small intestine (17). Since this type of mutation is known to be induced by oxidized guanine ( $8 \mathrm{OHG})$, a possible cause could be an elevated level of this type of damage in the tissue, or an insufficient level of activity of the repair gene Oggl which is responsible for the removal of $8 \mathrm{OHG}$ (26). An increase in a unique type of mutation in old mice was also observed in the epithelial tissues of the distal part of the small intestine and colon, where the frequencies of multiple mutations were elevated. A multiple mutation means an occurrence of two or more simple mutations at separate positions in a single lac $Z$ gene. Although this type of mutation was found in many tissues, the frequencies of appearance were too low to be used for an evaluation of its characteristics (27). In the digestive tract of Muta ${ }^{\mathrm{TM}}$ mice, the multiple mutations contained more A:T to G:C and T:A to G:C base substitutions. These were reported to be induced by an increase of the dCTP pool (28) or by translesional DNA synthesis utilizing Rev1 (29,30). A tandem base mutation, which means two base substitutions at two neighboring bases, is another type of mutation which is reported to increase with age in liver, kidney and adipose tissues (19). This type of mutation has been reported to be induced by many agents such as acetaldehyde, acrolein, hydroxyl radicals, etc. (19), so, it is difficult to specify a cause. These results are summarized in Table 2 .

An increase of mutant frequencies in the hearts of old mice is interesting because the tissue consists mostly of terminally differentiated non-proliferating cells. As was described in the introduction, DNA damage itself is not necessarily a mutation; a mutation is formed through an

Table 2. Increases in unique types of mutations in the tissues of old mice

\begin{tabular}{lll}
\hline \multicolumn{1}{c}{ Tissue } & \multicolumn{1}{c}{ Elevated mutation } & Possible cause of mutation \\
\hline Esophagus & $\begin{array}{l}\text { Deletion at } \\
\text { repeated sequences (17) }\end{array}$ & Insufficiency of MMR (24) \\
$\begin{array}{l}\text { Proximal- and } \\
\text { medial-small intestine }\end{array}$ & G:C to T:A (17) & 8OHG (11) \\
$\begin{array}{c}\text { Distal-small } \\
\text { intestine and colon }\end{array}$ & Multiple mutations (17) & Insufficiency of Ogg1 (26) \\
$\begin{array}{c}\text { Kidney, liver and } \\
\text { adipose tissue }\end{array}$ & Tandem mutations (14,19) & Elevation d pool (28) \\
Involvemt of Rev1 (29, 30) \\
\end{tabular}


error in DNA repair or as a result of the replication of damaged DNA. Recently, a type of DNA repair called non-homologous end-joining which acts on double strand breaks has been found to be error-prone, and thus capable of creating mutations in the absence of DNA replication (4). This may indicate that DNA double strand breaks are present in heart cell DNA.

A very slight or no accumulation of mutations in the brain, skin and testis of old mice indicates that genomic integrity in these tissues is very efficiently protected. However, repeated exposure of mice to X-rays results in DNA damage and induction of mutations in the brain and testis at levels similar to those induced in liver and spleen (31). Thus, the high levels of maintenance or protection of genome integrity observed in brain, skin and testis may be interpreted to mean that repair is limited to types of damage which are not induced by radiation.

\section{Effects of DNA repair capability}

Another approach to understanding the reasons for tissue-specificity in the maintenance of genome integrity is to examine the effect of deficiencies in specific repair genes on mutation levels. Currently, many kinds of DNA repair genes are knocked out in mice, and the effects of these gene deficiencies can be observed (32). Some of these knock-out mice show embryonic lethality, developmental failure, or a high incidence of cancer. Mice deficient in the Erccl, Ttd, DNA-Pkcs or Ku86 genes display a phenotype showing accelerated senescence $(33,34)$. Erccl and Ttd are involved in nucleotide excision repair (NER) of bulky DNA base damage, while $D N A$-Pkcs and Ku86 are involved in the nonhomologous end joining (NHEJ) repair of DNA double strand breaks. Thus it is of interest to know if these phenotypes are associated with genomic instability or elevated mutation levels are caused by a defect in a single DNA repair gene. The answer to this question is not yet clear because genomic stability has not been studied extensively in these mice. In the studies utilizing these knock-out mice, spontaneous mutation levels have been examined in animals which revealed no obvious phenotypic alterations (35), and all of these results showed little or no increases in mutation levels. An exception to this were animals deficient in some of the genes involved in mismatch repair. These animals showed highly elevated mutation rates in many tissues, and only survived several months before they died of cancer (35).

In 1999, Giese et al. examined mutations in Xpa deficient mice and found that there was no effect of this deficiency in young ages in either the liver or the brain (36). At 12 months of age, however, mutant frequencies were elevated about 2 -fold in the liver over that seen in wild type mice of the same age, but mutation levels in the brain were not affected. This data indicates that the $X p a$ gene is probably indispensable for the maintenance of genome integrity in the liver but not in the brain. This could explain the fact that liver tumor incidence rates are elevated in $\mathrm{Xpa}$-deficient mice (37).

A similar study was done on $X p c$-deficient mice. Wijinhoven et al. reported that mutant frequency in the $H p r t$ gene in the spleen of $X p c(-/-)$ mice was similar to that of $X p c(+/+)$ mice at young age but became elevated at middle age (38). Since both Xpc and Xpa are involved in nucleotide excision repair (NER), the results in $X p c(-/-)$ and $X p a(-/-)$ mice seem to correspond well. However, NER is known to comprise two pathways; repair in non-transcribed regions called global genome repair or GGR, and repair in transcribed regions called transcription-coupled repair or TCR (1). $\mathrm{Xpc}$ is involved in the recognition of DNA damage in the GGR repair pathway, while the Hprt gene used for mutation assay is in a transcriptionally active state in spleen. Thus the increase of mutations in the Hprt gene in $X p c(-/-)$ mice cannot be explained by the present NER model since the $X p c$ gene may not be involved in the repair of the Hprt in this organ. However, it may be possible that the NER process in tissues or organs might be different from that functioning in cultured cells which have been used for studies of the NER process. More recently, Hollander et al. reported that Xpc $(-/-)$ mice develop benign lung tumors when the mice become old (39). They also found a high frequency of DNA loss in the $X P C$ gene region in human lung cancer, and suggested that $X p c$ gene expression is indispensable for the prevention of cancer development, at least in lung. To date, no data is available on the role of $X p c$ in the maintenance of genome integrity in the lung.

The studies on $X p a$ - and $X p c$-deficient mice suggest that the level of NER activity is different in different tissues, and these differences are not obvious at young ages but become pronounced at later stages in life. Future studies on mutations in different types of repair deficient mice could provide more information on which genes are functioning in each tissue for the purpose of maintaining genomic integrity. Similar types of future studies focusing on DNA protection system will also be important in helping us understand tissue-specific maintenance of genomic integrity.

Acknowledgements: The authors thank Dr L. N. Kapp for his editorial help. This work was supported partly by a Grant-in-Aid for Scientific Research and the Budget for Nuclear Research from the Ministry of Education, Culture, Sports, Science and Technology of Japan.

\section{References}

1 Christmann M, Tomicic MT, Roos WP, Kaina B. 
Mechanisms of human DNA repair: an update. Toxicology 2003; 193: 3-34.

2 Wood RD, Mitchell M, Sgouros J, Lindahl T. Human DNA repair genes. Science 2001; 291: 1284-9.

3 Rattray AJ, Strathern JN. Error-prone DNA polymerases: When making a mistake is the only way to get ahead. Annu Rev Genet. 2003; 37: 31-66.

4 Lieber MR, Ma Y, Pannicke U, Schwarz K. Mechanism and regulation of human non-homologous DNA endjoining. Nature Rev. 2003; 4: 712-20.

5 Vinson RK, Hales BF. DNA repair during organogenesis. Mutat Res. 2002; 509: 79-91.

6 Nouspikel T, Hanawalt PC. Terminally differentiated human neurons repair transcribed genes but display attenuated global DNA repair and modulation of repair gene expression. Mol Cell Biol. 2000; 20: 1562-70.

7 Nouspikel T, Hanawalt PC. DNA repair in terminally differentiated cells. DNA Repair 2002; 1: 59-75.

8 Hashimoto Y, Ono T, Okada S. Radiosensitivities of DNA molecules in lymphocytes from the circulating blood of man. Blood 1975; 45: 503-9.

9 Bielas JH, Heddle A. Proliferation is necessary for both repair and mutation in transgenic mouse cells. Proc Natl Acad Sci USA. 2000; 97: 11391-6.

10 Arai T, Kelly VP, Komoro K, Minowa O, Noda T, Nishimura S. Cell proliferation in liver of $\mathrm{Mmh} / \mathrm{Oggl}$ deficient mice enhances mutation frequency because of the presence of 8-hydroxyguanine in DNA. Cancer Res. 2003; 63: 4287-92.

11 Cheng KC, Cahill DS, Kasai H, Nishimura S, Loeb LA. 8-hydroxyguanine, an abundant form of oxidative DNA damage, causes $\mathrm{G} \rightarrow \mathrm{T}$ and $\mathrm{A} \rightarrow \mathrm{C}$ substitutions. $\mathrm{J}$ Biol Chem. 1992; 267: 166-72.

12 Nohmi T, Suzuki T, Masumura K. Recent advances in the protocols of transgenic mouse mutation assays. Mutat Res. 2000; 455: 191-215.

13 Gondo Y, Shioyama Y, Nakao K, Katsuki M. A novel positive dectection system of in vivo mutations in rpsL (strA) transgenic mice. Mutat Res. 1996; 360: 1-14.

14 Hill KA, Halangoda A, Heinmoeller PW, Gonzalez K, Chitaphan C, Longmate J, Scaringe WA, Wang J-C, Sommer SS. Tissue-specific time courses of spontaneous mutation frequency and deviations in mutation pattern are observed in middle to late adulthood in Big-Blue mice. Environ Mol Mutagen. 2005; 45: 442-54.

15 Gossen JA, de Leeuw WJF, Verwest A, Lohman PHM, Vijg J. High somatic mutation frequencies in a LacZ transgene integrated on the mouse X-chromosome. Mutat Res. 1991; 250: 423-9.

16 Leach EG, Gunther EJ, Yeasky TM, Gibson LH, YangFeng TL, Glazer PM. Frequent spontaneous deletions at a shuttle vector locus in transgenic mice. Mutagenesis 1996; 11: 49-56.

17 Ono T, Ikehata H, Pithani VP, Uehara Y, Chen Y, Kinouchi Y, Shimosegawa T, Hosoi Y. Spontaneous mutations in digestive tract of old mice show tissuespecific patterns of genomic instability. Cancer Res. 2004; 64: 6919-23.

18 Ono T, Ikehata H, Nakamura S, Saito Y, Hosoi Y, Takai Y, Yamada S, Onodera J, Yamamoto K. Age-associated increase of spontaneous mutant frequency and molecular nature of mutation in newborn and old lacZ-transgenic mouse. Mutat Res. 2000; 447: 165-77.

19 Hill KA, Wang J, Farwell KD, Sommer SS. Spontaneous tandem-base mutations (TBM) show dramatic tissue, age, pattern and spectrum specificity. Mutat Res. 2003; 534: $173-86$.

20 Millar CB, Guy J, Sansom OJ, Selfridge J, MacDougall E, Hendrich B, Keightley PD, Bishop SM, Clarke AR, Bird A. Enhanced $\mathrm{CpG}$ mutability and tumorigenesis in MBD4-deficient mice. Science 2002; 297: 403-5.

21 Ikehata H, Masuda T, Sakata H, Ono T. Analysis of mutations spectra in UVB-exposed mouse skin epidermis and dermis: Frequenct occurrence of $\mathrm{C} \rightarrow \mathrm{T}$ transition at methylated $\mathrm{CpG}$-associated dipyriumidine sites. Env Mol Mutagen. 2003; 41: 280-92.

22 Ikehata $\mathrm{H}$, Kudo H, Masuda T, Ono T. UVA induces $\mathrm{C} \rightarrow \mathrm{T}$ transitions at methyl-CpG-associated dipyrimidine sites in mouse skin epidermis more frequently than UVB. Mutagenesis 2003; 18: 511-9.

23 Ono T, Ikehata H, Nakamura S, Saito Y, Komura J, Hosoi Y, Yamamoto K. Molecular nature of mutations induced by a high dose of X-rays in spleen, liver, and brain of the lacZ-transgenic mouse. Environ Mol Mutagen. 1999; 34: 97-105.

24 Buermeyer AB, Deschenes SM, Baker SM, Liskay RM. Mammalian DNA mismatch repair. Annu Rev Genet. 1999; 33: 533-64.

25 Furuno-Fukushi I, Masumura K, Furuse T, Noda Y, Takahagi M, Saito T, Hoki Y, Suzuki H, Wynshaw-Boris A, Nohmi T, Tatsumi K. Effect of Atm disruption on spontaneously arising and radiation-induced deletion mutations in mouse liver. Radiat Res. 2003; 160: 549-58.

26 Minowa O, Arai T, Hirano M, Monden Y, Nakai S, Fukuda M, Itoh M, Takano H, Hippou Y, Aburatani H, Masumura K, Nohmi T, Nishimura S, Noda $T$. Mmh/Oggl gene inactivation results in accumulation of 8-hydroxyguanine in mice. Proc Natl Acad Sci USA. 2000; 97: 4156-61.

27 Hill KA, Wang J, Farwell KD, Scaringe WA, Sommer SS. Spontaneous multiple mutations show both proximal spacing consistent with chronocoordinate events and alterations with p53-deficiency. 2004; 554: 223-40.

28 Phear G, Meuth M. A novel pathway for transversion mutation induced by dCTP misincorporation in a mutator strain of $\mathrm{CHO}$ cells. Mol Cell Biol. 1989; 9: $1810-2$.

29 Masuda Y, Takahashi M, Tsunekuni N, Minami T, Sumii M, Miyagawa K, Kamiya K. Deoxycytidyl transferase acivity of the human REV1 protein is closely associated with the conserved polymerase domain. J Biol Chem. 2001; 276: 15051-8.

30 Zhang Y, Wu X, Rechkoblit O, Geacintov NE, Tayler J-S, Wang Z. Response of human REV1 to different DNA damage: preferential dCMP insertion opposite the lesion. Nucleic Acids Res. 2002; 30: 1630-8.

31 Ono $T$, Ikehata H, Priya PV, Uehara Y. Molecular nature of mutations induced by irradiation with repeated low doses of X-rays in spleen, liver, brain and testis of lacZ-transgenic mice. Int J Radiat Biol. 2003; 79: 635-41. 
32 Friedberg EC, Meira LB. Database of mouse strains carrying targeted mutations in genes affecting cellular responses to DNA damage. Version 4. Mutat Res. 2000; 459: 243-74.

33 Hasty P, Campisi J, Hoeijmakers J, van Steeg H, Vijg J. Aging and genome maintenance: Lessons from the mouse? Science 2003; 299: 1355-9.

34 Espejel S, Martin M, Klatt P, Martin-Caballero J, Flores JM, Blasco MA. Shorter telomeres, accelerated ageing and increased lymphoma in DNA-PKcs-deficient mice. EMBO reports 2004; 5: 503-9

35 Ono T, Uehara Y, Saito Y, Ikehara H. Mutation theory of aging assessed in transgenic mice and knockout mice. Mech Age Develop. 2002; 123: 1543-52.

36 Giese H, Dolle MET, Hezel A, van Steeg H, Vijg J. Accelerated accumulation of somatic mutations in mice deficient in the nucleotide excision repair gene $X P A$. Oncogene 1999; 18: 1257-60.

37 de Vries A, van Oostrom CTM, Dortant PM, Beems RB, van Kreijl CF, Capel PJA, van Steeg H. Spontaneous liver tumors and benzo[a]pyrene-induced lymphomas in $X P A$-deficient mice. Mol Carcinogen. 1997; 19: 46-53.

38 Wijinhoven SWP, Kool HJM, Mullenders LHF, van Zeeland AA, Friedberg EC, van der Horst GTJ, van Steeg $\mathrm{H}$, Vrieling $\mathrm{H}$. Age-dependent spontaneous mutagenesis in $X p c$ mice defective in nucleotide excision repair. Oncogene 2000; 19: 5034-7.

39 Hollander MC, Philburn RT, Patterson AD, VelascoMiguel S, Friedberg EC, Linnoila RI, Fornace Jr AJ. Deletion of $X P C$ leads to lung tumors in mice and is associated with early events in human lung carcinogenesis. Proc Natl Acad Sci USA. 2005; 102: 13200-5. 